\title{
An Intervention Based Prevention of Catheter Associated Blood Stream Infection in Adult Critical Care Unit
}

\author{
${\text { Pravin Charles Marie } \text { Victor }^{1} \text { (D), Kalaivani Ramakrishnan }}^{1 *}$ (D), \\ Mohammad Hanifa ${ }^{2}$, Joshy Maducollil Easow ${ }^{1}$ and Jayapal Venugopal ${ }^{1}$
}

${ }^{1}$ Department of Microbiology, ${ }^{2}$ Department of Critical Care Medicine, Mahatma Gandhi Medical College and Research Institute, Sri Balaji Vidyapeeth, Deemed-to be-University, Puducherry, India.

\begin{abstract}
Central line associated blood stream infection (CLABSI) is a device associated infection posing a serious threat among critically ill patients. It also increases the cost of hospital stay, morbidity and mortality. The aim of the study was to implement bundle care approach and identify CLABSI rates post intervention in comparison with the retrospective data. All the patients who were admitted in the ICU with central line $(\mathrm{CL})$ in place were included in our study. The bundle care approach was implemented for all the patients when $C L$ was introduced. We compared the CLABSI rates during the implementation period with the previous year CLABSI rates. The CLABSI rates were compared during the pre-intervention and during the intervention. The pre-intervention rate was 7.48 per 1000 catheter days, whereas the post intervention rates were 1.01 and zero per 1000 catheter days. The etiological agents isolated from CLABSI were Enterobacter aerogenes (30\%) followed by Klebsiella pneumonia (20\%) and Pseudomonas aeruginosa (20\%). Similarly the antibiotic resistance was highest in ceftriaxone $(55.5 \%)$ and lowest in piperacillin tazobactam (11.1\%). A strict adherence to bundle care and proper education of the ICU team members including the doctors and nurses would effectively reduce infection rates. The CLABSI rates were 7.48 per 1000 catheter days in the previous year. However after implementation of bundle care the CLABSI rates reduced to zero.
\end{abstract}

Keywords: Central line, Bundle care, Infection control, CLABSI rate.

*Correspondence: kalaimicro21@gmail.com

(Received: 02 October 2019; accepted: 04 November 2019)

Citation: Pravin Charles Marie Victor, Kalaivani Ramakrishnan, Mohammad Hanifa, Joshy Maducollil Easow and Jayapal Venugopal, An Intervention Based Prevention of Catheter Associated Blood Stream Infection in Adult Critical Care Unit, J Pure App/ Microbiol., 2019; 13(4):2209-2214. https://doi.org/10.22207/JPAM.13.4.34

(C) The Author(s) 2019. Open Access. This article is distributed under the terms of the Creative Commons Attribution 4.0 International License which permits unrestricted use, sharing, distribution, and reproduction in any medium, provided you give appropriate credit to the original author(s) and the source, provide a link to the Creative Commons license, and indicate if changes were made. 


\section{INTRODUCTION}

The infections which are acquired 48 hours post admission to the hospital and not in incubation at the time of admission to the hospital are termed as Health Care Associated Infections (HAls). It is quite alarming that Device associated infections contribute a majority of HAls. Out of which Central Line Associated Blood Stream Infection (CLABSI) pose a serious threat and increases the cost of hospital stay, morbidity and mortality among the hospitalized patients ${ }^{1}$. A central line is an intravenous access device which is introduced into the great vessels of the heart for diverse purposes such as administration of medication, intravenous fluids, blood products and total parenteral nutrition among critically ill patients ${ }^{2}$. However it is crucial that blood stream infections arise as a sequel of central line in place. The risk factors for CLABSI include host factor, interventional factor and catheter related factors. Often a breach in aseptic precautions during insertion and handling leads to infection ${ }^{3}$. Comparatively the infection rates are higher among the developing countries rather than the developed countries. As per the International Nosocomial Infection Control Consortium (INICC) there is a fivefold rise in infection rates compared to United States ${ }^{4}$. In a study conducted in North India the mortality rate was $56 \%$. A strict surveillance and bundle care approach can prevent such infection rates and mortality among critically ill patients. The aim of the study was to implement bundle care approach and identify CLABSI rates post intervention in comparison with the retrospective data.

\section{MATERIALS AND METHODS Study design}

The study was conducted from January 2016 to December 2018 at our tertiary care hospital in Puducherry. The study population incudes all adult patients admitted with various surgical and medical conditions at the intensive care units (ICUs). Central Line (CL) insertion done as a part of their Medical management by our Critical care specialists and to whom the Central line were at place in-situ for at least 48 hours were only included in this study. The bundle care approach was implemented for all the patients when $C L$ was planned to introduce. We followed CDC guidelines for implementation of bundle care ${ }^{5}$. The prevention bundle was observed in two phases as insertion phase and maintenance phase (Table 1, 2). The insertion

Table 1. Insertion bundle

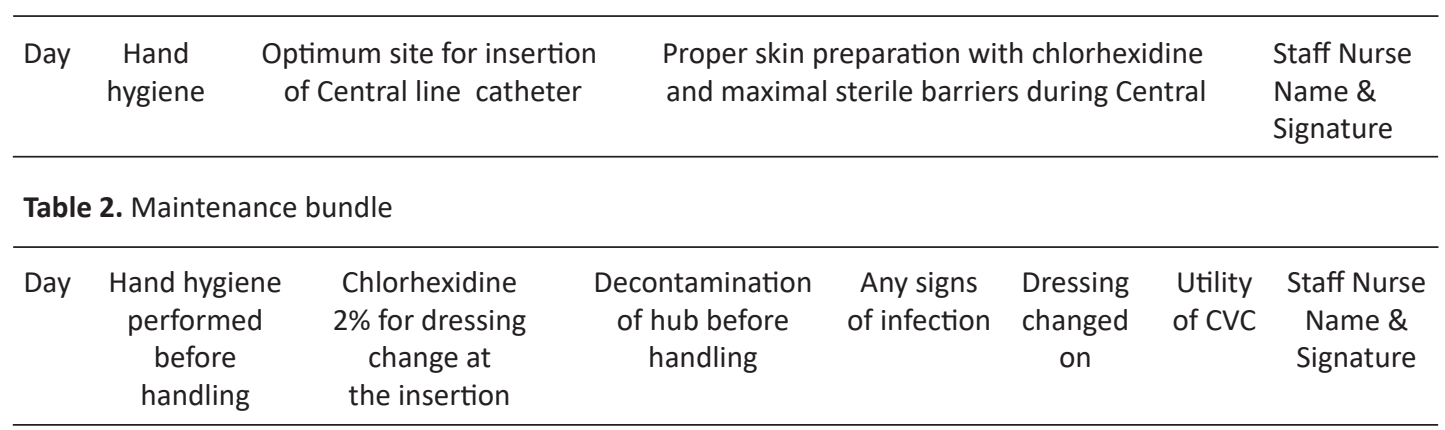

Table 3. CLABSI rates during the pre-intervention and intervention period

\begin{tabular}{lccc}
\hline CLABSI data & $\begin{array}{c}\text { Pre- } \\
\text { intervention }\end{array}$ & Intervention \\
\hline CLABSI episodes & 2016 & 2017 & 2018 \\
Catheter days & 9 & 1 & 0 \\
CLABSI rate & 1202 & 987 & 879 \\
& 7.48 & 1.01 & 0
\end{tabular}

phase included proper hand hygiene, optimum site for insertion of catheter, proper skin preparation with chlorhexidine and maximal sterile barriers during insertion. The maintenance bundle included hand hygiene, sterile dressing change and aseptic accession of the $\mathrm{CL}$ with periodic review for the line in place ${ }^{6}$. We compared the CLABSI rates during the implementation period 
with the previous year CLABSI rates.

\section{CLABSI identification}

CLABSI was identified when any laboratory confirmed pathogen isolated 48 hours after the $\mathrm{CL}$ insertion from one or more percutaneous blood culture, provided no other source of infection was identified?

\section{Data collection}

The ICU nurses and doctors were trained to follow bundle care approach. The bundle adherence was verified by a checklist distributed among the ICU nurses. The study was done with co-operation of the hospital infection control team at our institute. The maintenance phase was critically observed by the infection control nurses and liaison nurses regularly.

In case of suspected infection, around 5 to $10 \mathrm{ml}$ of blood was collected from patients in brain heart infusion broth (BHI) and sub-cultured on blood agar, Mac-conkey agar and chocolate agar after $24 \mathrm{hrs}, 48 \mathrm{hrs}$ and one week of aerobic incubation ${ }^{8}$. The organisms were identified by standard bacteriological procedure. The antimicrobial sensitivity was identified by KirbyBauer disc diffusion method.

\section{Statistical methods}

The CLABSI rate during the intervention period was compared with the previous rate. The statistical analysis was done with SPSS for windows version 16 . The CLABSI rates were calculated by the formula total number of CLABSI episodes per thousand central line days. $p$ value was calculated by Repeated measures Anova test.

\section{RESULTS}

The CLABSI rates during the preintervention and intervention period is shown in the table 3, 4 and Fig. 1.

\section{Month wise distribution of CLABSI rates}

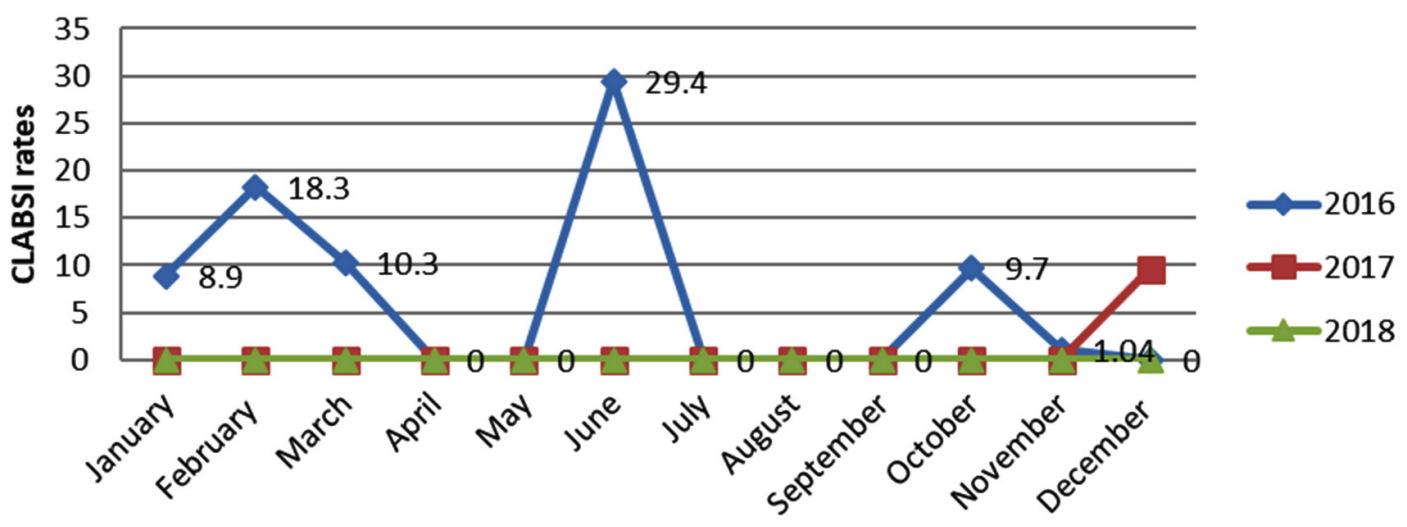

Fig. 1. Month-wise distribution of CLABSI rate

Table 4. Quarterly distribution of CLABSI rates

\begin{tabular}{|c|c|c|c|c|c|c|c|c|c|}
\hline \multirow[t]{3}{*}{ Months } & \multicolumn{3}{|c|}{$\begin{array}{c}\text { Number of CLABSI } \\
\text { cases }\end{array}$} & \multicolumn{3}{|c|}{$\begin{array}{l}\text { Total number of } \\
\text { central line days }\end{array}$} & \multicolumn{3}{|c|}{$\begin{array}{l}\text { CLABSI } \\
\text { rate }\end{array}$} \\
\hline & \multirow{2}{*}{$\begin{array}{c}\text { Pre- } \\
\text { intervention } \\
2016\end{array}$} & \multicolumn{2}{|c|}{ Intervention } & \multirow{2}{*}{$\begin{array}{c}\text { Pre- } \\
\text { intervention } \\
2016\end{array}$} & \multicolumn{2}{|c|}{ Intervention } & \multirow{2}{*}{$\begin{array}{c}\text { Pre- } \\
\text { intervention } \\
2016\end{array}$} & \multicolumn{2}{|c|}{ Intervention } \\
\hline & & 2017 & 2018 & & 2017 & 2018 & & 2017 & 2018 \\
\hline $\begin{array}{l}\text { January to } \\
\text { April }\end{array}$ & 4 & 0 & 0 & 408 & 329 & 341 & 9.08 & 0 & 0 \\
\hline $\begin{array}{l}\text { May to } \\
\text { August }\end{array}$ & 3 & 0 & 0 & 413 & 255 & 251 & 7.26 & 0 & 0 \\
\hline $\begin{array}{l}\text { September to } \\
\text { December }\end{array}$ & 2 & 1 & 0 & 381 & 403 & 287 & 5.24 & 2.48 & 0 \\
\hline
\end{tabular}


Table 5. Etiological agents for CLABSI

\begin{tabular}{lcc}
\hline Organism & Frequency & Percentage \\
\hline Acinetobacter baumannii & 1 & $10 \%$ \\
Klebsiella pneumoniae & 2 & $20 \%$ \\
Pseudomonas aeruginosa & 2 & $20 \%$ \\
Enterobacter aerogenes & 3 & $30 \%$ \\
Escherichia coli & 1 & $10 \%$ \\
Staphylococcus, & 1 & $10 \%$ \\
coagulase negative & 10 & $100 \%$ \\
Total & 10 \\
\hline
\end{tabular}

The CLABSI rates were compared with the preintervention period and $p$ value was calculated by using Repeated measures Anova test. The $p$ value was $<0.001$ which was statistically significant.

The etiological agents isolated from CLABSI are shown in table 5. The common organism isolated were Enterobacter aerogenes (30\%) followed by Klebsiella pneumonia (20\%) and Pseudomonas aeruginosa (20\%). Similarly the antibiotic resistance is shown in table 6 . The resistance was highest in ceftriaxone (55.5\%) and lowest in piperacillin tazobactam (11.1\%).

\section{DISCUSSION}

CLABSI is a blood stream infection with a $\mathrm{CL}$ in place for more than two calendar days. This term has been endorsed by the National Health care Safety Network (NHSN) for surveillance purpose. The patient should have signs of sepsis such as fever, chills and hypotension, with a positive culture from $\mathrm{CL}$ and peripheral line.

Device Associate Infection is a major threat increasing the morbidity and mortality among critically ill patients. A care bundle involves a set of sequential steps which focus both infection prevention and control. It aims at a prompt delivery of quality clinical care ${ }^{9}$. Quite often the breach in the continuity of the skin acts as a source of infection. In addition, frequent intervention by the health care team also acts as a source of infection.

Implementation of proper bundle care for $\mathrm{CL}$ has reduced the CLABSI rates as reported from various studies around the world.
Table 6. Susceptibility pattern of isolates

\begin{tabular}{lc}
\hline Antibiotic & $\begin{array}{c}\text { Resistance } \\
\text { percentage of } \\
\text { isolates n=9 }\end{array}$ \\
\hline Ceftriaxone & $5(55.5 \%)$ \\
Piperacillin & $1(11.1 \%)$ \\
tazobactam & \\
Ciprofloxacin & $3(33.3 \%)$ \\
Cotrimoxazole & $4(44.4 \%)$ \\
Amikacin & $2(22.2 \%)$ \\
Gentamicin & $3(33.3 \%)$ \\
Imipenem & $4(44.4 \%)$ \\
Meropenem & $2(22.2 \%)$ \\
\hline
\end{tabular}

In a study conducted in Columbia there was a significant reduction in CLABSI rate of $73 \%$ after intervention ${ }^{10}$. Similar other studies from New Zealand and Kuwait have proved reduction in CLABSI rates from 3.32 to 0.28 per 1000 catheter days and 14.9 to 11.08 per 1000 catheter days respectively ${ }^{11,12}$. In India around $53 \%$ reduction in CLABSI rates had been proven with CLABSI rates from 6.4 to 3.9 per 1000 catheter days. These studies show a positive impact on bundle care approach to prevent CLABSI ${ }^{13}$. With available data, developing countries can also prevent infection rate with strict adherence to the bundle care in comparison to the developed countries.

However the aim of bundle care is to totally curb CLABSI rate to zero. The zero CLABSI rate though attained has to be sustained so that mortality is reduced.

In this study we aimed at reduction of CLABSI in comparison to the previous year. The CLABSI rates were 7.48 per 1000 catheter days in the previous year. However after implementation of bundle care the CLABSI rates reduced to zero. There are studies which show that zero rates could be attained and sustained with proper bundle care $^{14,15}$.

The common organism isolated were Enterobacter aerogenes (30\%) followed by Klebsiella pneumonia (20\%) and Pseudomonas aeruginosa (20\%). However in contrast, based on NHSN data the common organism isolated are Gram-positive organisms such as coagulasenegative staphylococci which accounts for 34.1\%; followed by Klebsiella, Enterobacter and Pseudomonas which accounts for $5.8 \%, 3.9 \%$ and 
$3.1 \%$ respectively ${ }^{16,17}$. In this present study the common isolates were Gram negative followed by gram positive organism.

\section{CONCLUSION}

CLABSI is a device associated blood stream infection which can be prevented by strict bundle care adherence. A proper education of the ICU team members including the doctors and nurses would effectively reduce infection rates. However to sustain reduced CLABSI rates ample support from the ICU team in cooperation with the infection control team is mandate.

\section{ACKNOWLEDGEMENTS}

The authors sincerely acknowledge Mahatma Gandhi Medical College and Research Institute, Sri Balaji Vidyapeeth (SBV) Deemed -to be- University for supporting this faculty project. We wholeheartedly thank our Medical Superintendent for permitting the authors to carry out this study successfully. Finally we thank all our Infection Control Nurses for their active role throughout this study.

\section{CONFLICT OF INTEREST}

The authors declare that there is no conflict of interest.

\section{AUTHOR'S CONTRIBUTION}

$\mathrm{PCMV}$ is the Primary investigator and $\mathrm{KR}$ is the Co. Investigator in this study. PCMV did the literature review and carried out this study. KR and VJ also intellectually contributed to this study and involved in all training programs. PCMV compiled and analyzed the data. MH and JME act as quality control officers. PCMV drafted the manuscript. All authors read and approved the manuscript for publication.

\section{FUNDING}

None.

\section{DATA AVAILABILITY}

All datasets generated and analyzed during this study are included in the manuscript.

\section{ETHICS STATEMENT}

Institute Research Committee and Institute Human Ethical Committee approval was obtained for conducting this study and to publish the findings.

\section{REFERENCES}

1. Park et al. Antimicrobial Resistance and Infection Control, 2017; 6: 103 DOI 10.1186/s13756-017-0263-3.

2. Wilson C. Preventing central venous catheter-related bloodstream infection. Nurs. Stand., 2015; 29: 37-43. https://doi.org/10.7748/ns.29.19.37.e9271

3. Septimus EJ and Moody J. Prevention of DeviceRelated Healthcare-Associated Infections [version 1; referees: 2approved] F1000Research 2016; 5(F1000 Faculty Rev): 65 https://doi.org/10.12688/ f1000research.7493.1

4. Mishra SB, Misra R, Azim A, Baronia AK, Prasad KN, Dhole TN, Gurjar M, Singh RK, Poddar B. Incidence, risk factors and associated mortality of central lineassociated bloodstream infections at an intensive care unit in northern India. Int. J. Qual. Health Care, 2017; 29(1): 63-67. https://doi.org/10.1093/intqhc/mzw144

5. Pogorzelska M, Stone PW, Furuya EY, Perencevich EN, Larson EL, Goldmann D, et al. Impact of the ventilator bundle on ventilator-associated pneumonia in Intensive Care Unit. Int. J. Qual. Health Care, 2011; 23: 538-44.[Last cited on 2016 Dec 01]. https://doi. org/10.1093/intqhc/mzr049

6. Tang HJ, Lin HL, Lin YH, Leung PO, Chuang YC, Lai CC. The impact of central line insertion bundle on central lineassociated bloodstream infection. BMC Infect. Dis., 2014; 14: 356. https://doi.org/10.1186/1471-2334-14356

7. Horan TC, Andrus M, Dudeck MA. CDC/NHSN surveillance definition of health care-associated infection and criteria for specific types of infections in the acute care setting. Am. J. Infect. Control, 2008; 36: 309-32. https://doi.org/10.1016/j.ajic.2008.03.002

8. Mackie TJ, McCartney JE. Practical medical microbiology. $14^{\text {th }}$ ed. New York: Churchill Livingstone; 1996.

9. Cooke FJ, Holmes $\mathrm{AH}$. The missing care bundle: Antibiotic prescribing in hospitals. Int. J. Antimicrob Agents, 2007; 30: 25-9. https://doi.org/10.1016/j. ijantimicag.2007.03.003

10. Alvarez-Moreno CA, Valderrama-Beltran SL, Rosenthal VD, Mojica-Carreno BE, Valderrama-Marquez IA, Matta-Cortes L, et al. Multicenter study in Colombia: impact of a multidimensional International Nosocomial Infection Control Consortium (INICC) approach on central line-associated bloodstream infection rates. Am. J. Infect. Control, 2016; 44: e235e41. https://doi. org/10.1016/j.ajic.2016.03.043

11. Gray J, Proudfoot S, Power M, Bennett B, Wells S, Seddon M. Target CLAB Zero: a national improvement collaborative to reduce central line-associated bacteraemia in New Zealand intensive care units. N.Z. Med. J., 2015; 128: 13e21.

12. Salama MF, Jamal W, Al Mousa H, Rotimi V. Implementation of central venous catheter bundle in an intensive care unit in Kuwait: effect on central line-associated bloodstream infections. J Infect Public Health, 2016; 9: 34e41. https://doi.org/10.1016/j. 
jiph.2015.05.001

13. Jaggi N, Rodrigues C, Rosenthal VD, Todi SK, Shah S, Saini N, et al. Impact of an international nosocomial infection control consortium multidimensional approach on central lineassociated bloodstream infection rates in adult intensive care units in eight cities in India. Int. J. Infect. Dis., 2013; 17: e1218e24.

14. Hakko E, Guvenc S, Karaman I, Cakmak A, Erdem T, Cakmakci M. Long-term sustainability of zero centralline associated bloodstream infections is possible with high compliance with care bundle elements. East Mediterr Health J., 2015; 21: 293e8. https://doi. org/10.26719/2015.21.4.293

15. Erdei C, McAvoy LL, Gupta M, Pereira S, McGowan EC. Is zero central line-associated bloodstream infection rate sustainable? A 5-year perspective. Pediatrics, 2015; 135: e1485e93. https://doi.org/10.1542/peds.20142523

16. Atilla A, Doganay Z, Kefeli Celik H, Demirag MD, S Kilic S. Central line-associated blood stream infections: characteristics and risk factors for mortality over a 5.5year period. Turk. J. Med. Sci., 2017; 47(2): 646-652. https://doi.org/10.3906/sag-1511-29

17. Wright MO, Decker SG, Allen-Bridson K, Hebden $J N$, Leaptrot D. Healthcare-associated infections studies project: An American Journal of Infection Control and National Healthcare Safety Network data quality collaboration: Location mapping. Am. J. Infect. Control, 2018; 46(5): 577-578. https://doi. org/10.1016/j.ajic.2017.12.012 